\title{
APRENDIZAGEM EM GEOMETRIA NA EDUCAÇÃO BÁSICA: A FOTOGRAFIA E A ESCRITA NA SALA DE AULA ${ }^{1}$
}

PAULA, Enio Freire de ${ }^{2}$

A recém lançada obra Aprendizagem em Geometria na educação básica: a fotografia e a escrita em sala de aula, das autoras Cleane Aparecida dos Santos e Adair Mendes Nacarato, integra a renomada coleção Tendências em Educação Matemática³ , publicada pela Autêntica Editora. O livro em questão é fruto da dissertação ${ }^{4}$ da primeira autora, orientada pela segunda e defendida em 2011 no Programa de Pós-graduação em Educação da Universidade São Francisco. A obra refere-se às atividades investigativas relacionadas ao processo de ensino aprendizagem de Geometria com alunos do $5^{\circ}$ ano de uma escola pública no município de Jundiaí, estado de São Paulo.

Ao enfatizarem a urgente necessidade de realização de investigações relacionadas a essa temática, as autoras pontuam que a escassez de materiais de apoio aos professores dos anos inicias para o ensino de geometria, as lacunas conceituais dos cursos de Pedagogia no Brasil frente aos conceitos geométricos e também a ausência de disciplinas nesses cursos que tratem especificamente desse assunto ainda na formação inicial, foram fatores motivadores para a escrita do livro. Outro ponto em destaque já na Introdução e evidenciado no decorrer da leitura dos demais oito capítulos que compõem a obra, é o fato de narrar sobre uma experiência realizada no chão da escola, caracterizada pelas inquietações da pesquisadora. De acordo com Santos e Nacarato (2104, p. 10)

\footnotetext{
[...] o professor da escola básica busca um mestrado para investigar questões importantes para o exercício da sua profissão. Ao realizar a pesquisa, esse professor não adquire simplesmente, um saber do conteúdo: o movimento que vivencia entre a escola e a academia, nas trocas com os alunos e com os pares acadêmicos, vai lhe possibilitando a apropriação de um repertório de saberes para campos específicos do conhecimento matemático. Uma pesquisa de mestrado ou doutorado que toma a própria prática como objeto de investigação constitui um espaço interessante de formação continuada.
}

\footnotetext{
${ }^{1}$ Resenha Livre da Obra: SANTOS, C.A.; NACARATO, A.M. Aprendizagem em Geometria na educação básica: a fotografia e a escrita na sala de aula. Belo Horizonte: Autêntica Editora, 2014.

${ }^{2}$ Instituto Federal de Educação, Ciência e Tecnologia do Estado de São Paulo - IFSP - Presidente Epitácio - São Paulo - Brasil.

${ }^{3}$ A coleção Tendências em Educação Matemática é coordenada pelo Prof. Dr. Marcelo de Carvalho Borba, docente do Programa de Pós-graduação em Educação Matemática da UNESP, Rio Claro/SP e reúne atualmente 29 títulos, escritos por renomados pesquisadores da área, a respeito dos campos de investigação integrantes da Educação Matemática. Mais informações sobre os livros que compõem a coleção são encontradas no site da editora: http://grupoautentica.com.br/autentica/colecoes/16.

${ }^{4}$ SANTOS, Cleane Aparecida. Fotografar, escrever e narrar: a elaboração conceitual em Geometria por alunos do quinto ano do ensino fundamental. 2011. 185p. Dissertação (Mestrado em Educação) - Universidade São Francisco. Disponível em <http://www.usf.edu.br/publicacoes/dissertacoes.vm?ano=2011\&programa=Educacao\#conteudoInternas $>$. Acesso em 10 out. 2015.
} 
Por considerarem o desenvolvimento da pesquisa como um processo de formação continuada, após a conclusão da mesma, as pesquisadoras, tal como narram na Introdução, ao identificarem o potencial das tarefas realizadas com os alunos, decidiram que elas deveriam ser compartilhadas com outros professores. A partir daí surgiu a ideia de produção do livro.

No capítulo de abertura, Uma breve trajetória sobre o ensino da Geometria e o pensamento algébrico, as autoras apresentam uma revisão histórica das diversas fases do ensino de geometria no Brasil, desde a influência da Geometria axiomática/euclidiana particularmente até meados da década de 1960, perpassando pela influência do Movimento da Matemática Moderna entre os anos 1970 e 1980 e os estudos piagetianos nas décadas de 1980 e 1990, utilizando como referência na maioria dos casos, os textos de Pavanello (1993, 2004). Nesse momento do texto, ao problematizarem os avanços das discussões frente ao desenvolvimento do pensamento geométrico (VAN DE WALLE, 2009), as autoras explicitam "[...] nosso foco neste trabalho está nas duas dimensões do pensamento geométrico: as noções espaciais (incluindo as topológicas) e as noções de formas (incluindo a geometria plana e a espacial)." (SANTOS E NACARATO, 2014, p. 16). Fato este que evidencia a preocupação das autoras em romper com o modelo euclidiano, valorizando a problematização, o uso adequado da linguagem, bem como de recursos didáticos, o que converge para a escolha epistemológica postulada pela teoria vigotskiana. As discussões referentes aos recursos didáticos são apoiadas pelos textos de Pais $(1996,2000)$ e encontram-se no livro em paralelo a diversas imagens de atividades realizadas com os alunos, bem como uma carta produzida por um aluno e direcionada a professora pesquisadora, em que se evidencia a apropriação de um vocabulário geométrico com significação por parte do aluno. Todos os esforços convergem para justificar a necessidade de propiciar aos alunos o contato com tarefas que apresentem os elementos centrais do pensamento geométrico experimentação, intuição e teoria - (PAIS, 1996) de modo indissociável.

A apresentação da escola é feita detalhadamente no segundo capítulo intitulado $A$ primeira fotografia: tecendo imagens com os atores da escola pautados num ambiente que rompe com o paradigma do exercício. Além disso, é relatado o ponto de partida para a investigação: (i) o registro fotográfico dos espaços escolares que pudessem ter alguma relação com a geometria (realizado pelos alunos mediante o uso de uma máquina digital disponibilizada pela professora) e (ii) a produção de textos pelos alunos justificando a foto realizada. As autoras ratificam a importância do trabalho em grupo e a necessidade de propiciarmos tarefas de escritas e leituras nas aulas de Matemática como subsídios para rompermos com a cultura das aulas pautadas no paradigma do exercício ${ }^{5}$, tal como discutido por Alrø e Skovsmose (2006).

\footnotetext{
5 "Esse paradigma tem grande influência na Educação Matemática no que diz respeito à organização das aulas, aos padrões de comunicação entre professore e alunos, bem como ao papel que a Matemática desempenha na sociedade como um todo, por exemplo, com uma função fiscalizadora (exercícios matemáticos encaixam-se perfeitamente em processos de seleção). Geralmente, exercícios de matemáticos são preparados por uma autoridade externa à sala de aula. Nem o professor, nem os alunos participam da elaboração dos exercícios. Eles são estabelecidos pelo autor de um livro-texto. Isso significa que a justificativa para a relevância dos exercícios não faz parte da lição em si mesma. Os textos e exercícios matemáticos costumam ser, para aqueles que vivenciam a prática e a comunicação em sala de aula, elementos pré-estabelecidos" (ALRǿ; SKOVSMOSE, 2006, p. 52, grifo nosso). Fornecer subsídios para que essa relação se modifique é o desafio dos professores de Matemática que desejam reverter essa visão tradicionalmente divulgada na sociedade
} 
Nos três capítulos seguintes (III, IV e V) encontramos as análises das tarefas realizadas. Em "Com uma câmera nas mãos, e agora? As percepções dos alunos sobre a escola", vemos que nas escritas-livres dos alunos é possível identificar seus sentimentos em relação ao ambiente escolar. Além disso, na maioria dos casos, essa foi a primeira experiência dos alunos com a escrita nas aulas de Matemática. Concordamos com as autoras que essa experiência unificou as discussões relacionadas aos conceitos geométricos com a ludicidade de tornar-se um "aluno-fotografo". Julgamos interessante também a menção das autoras em indicarem novas possibilidades investigativas após o resultado das fotografias dos alunos, em que poderiam ser discutidos outros aspectos como os conceitos de perspectiva, projeção e dimensionalidade por exemplo. Isso mostra que o trabalho investigativo realizado com os alunos, no "chão da escola" como elas dizem, pode apresentar resultados que, mesmo sendo de natureza inesperada, mostram-se como potencializadores de novas investigações. Embora as autoras pontuem, mediante as fotos feitas pelos alunos, que o projeto arquitetônico da escola é responsável por inviabilizar diversas atividades com eles, acreditamos que discutir as fotografias desses ambientes com os alunos, bem como suas narrativas a esse respeito, se apresentaria como uma problemática investigativa interessante para o relação fotografia-geometria. Esse fato, por si só, poderia gerar, a nosso ver, uma interessante investigação também realizada no ambiente escolar, em uma outra oportunidade, pelas próprias autoras, ou por outros interessados. Nas produções textuais dos alunos é possível encontramos indicadores da compreensão de que os objetos encontrados no cotidiano são apenas parecidos com os objetos geométricos, posto que os entes geométricos são abstrações e, portanto, não existem no mundo real.

Os cuidados da professora pesquisadora em suas intervenções a partir das narrativas dos alunos e em especial, suas reflexões a respeito da qualidade de suas devolutivas é um fator de destaque no quarto capítulo, intitulado Fotografia além da fotografia: evidenciando o processo de elaboração conceitual dos alunos. Como exemplo desse cuidado é apresentada uma intervenção não considerada boa, posto que a professora corrigiu a aluna, fornecendo a resposta correta de modo imediato, impossibilitando-a de pensar matematicamente a respeito de seu erro e chegar a resposta correta por seus próprios argumentos. Contudo, acreditamos que o processo de tornar públicas as reflexões desse episódio, demonstram o compromisso da pesquisadora com a qualidade do trabalho de investigação.

Enquanto nos capítulos III e IV as atividades concentraram-se nas tarefas de comparação entre os objetos do mundo real (concreto) e seus "semelhantes" geométricos (abstrato), o capítulo V, Registros: o escrito, o pictórico e a fotografia na constituição da percepção espacial pelos alunos, embora o menor do livro, traz novas visões frente a uma atividade costumeira dos bancos escolares: a construção de um croqui casa-escola. São explorados conceitos de geometria espacial mediante as fotografias dos pontos de referência do trajeto casa-escola feito por um dos alunos. Já $A$ leitura e a escrita: produzindo relatos, narrativas e cartas, o sexto capítulo, discute as características dialógicas decorrentes do uso de narrativas nas aulas de matemática. Segundo as autoras, essa estratégia possibilita aos alunos ampliarem suas reflexões a respeito de suas experiências matemáticas devido a 
escrita. Por fim, em Zoom: potencialidades reveladas pelo uso da máquina fotográfica e da escrita em sala de aula...o que ficou? São apresentadas as conclusões finais dessa prática investigativa.

Inspirados no título do último capítulo, concebemos outros questionamentos: $E$ para $O$ resenhista? O que ficou?

No decorrer de cada capítulo, evidenciamos um estudo cuja preocupação central não foi apenas tornar público aos professores que ensinam matemática (PEM) tarefas que possibilitem melhorias para o ensino de geometria na Educação Básica. O percurso narrativo, utilizado na obra, convida os leitores - casos sejam PEM - à uma reflexão ao mesmo tempo dialógica e diacrônica, frente o ensino de geometria, fato este que propicia aos docentes uma ampla discussão relacionada as dinâmicas e práticas em salas de aulas de Matemática. De mesmo modo, caso os leitores não sejam PEM atuantes, ou seja, ainda em formação inicial, Aprendizagem em Geometria na educação básica: a fotografia e a escrita em sala de aula traz lampejos de tarefas de geometria que infelizmente, muitos de nós, hoje professores, não vivenciamos enquanto alunos, independentemente do nível de escolaridade. São possibilidades que contrastam com um ensino de geometria meramente algébrico, escondido no final dos livros didáticos, em uma época não muito distante. O livro que ora resenhamos mostra-se uma obra singular e estruturada, com reflexões conscientes que evidenciam a necessidade urgente de novos paradigmas no processo de ensino aprendizagem não só de Geometria, mas sim da Matemática de modo geral: leitura recomendada a todos os professores que ensinam matemática.

\section{REFERÊNCIAS}

1. ALRǿ, Helle, SKOVSMOSE, Ole. Diálogo e Aprendizagem em Educação Matemática. Belo Horizonte: Autêntica, 2006.

2. PAIS, L.C. Intuição, experiência e teoria geométrica. Zetetiké: Cempem/FE/ Unicamp, Campinas, SP, v.4, n.6, p. 65-74, jul./dez. 1996.

3. PAIS, L.C. Uma análise do significado da utilização de recursos didáticos no ensino da geometria. In: REUNIÃO DA ANPED, 23,24 A 28 de setembro de 2000, Caxambu, MG. Disponível em http://www.anped.org.br/23textos/1919t.pdf. Acesso em 10 out. 2015.

4. PAVANELLO, R.M. O abandono do ensino da geometria no Brasil: causas e consequências. Zetetiké: Cempem/FE/ Unicamp, Campinas, SP, ano 1, n.1, p.7-17, 1993

5. PAVANELLO, R.M. A geometria nas séries iniciais do ensino fundamental: contribuições da pesquisa para o trabalho escolar. In: PAVANELLO, R.M. (org.). Matemática nas séries iniciais do ensino fundamental: a pesquisa e a sala de aula. São Paulo: SBEM, 2004, p. 129-143 (Coleção SBEM). 
6. VAN DE WALLE, J. A. A Matemática no ensino fundamental: formação de professores e aplicação em sala de aula. Porto Alegre: Artmed, 2009.

\section{Enio Freire de Paula:}

Licenciado em Matemática pela FCT/UNESP, campus de Presidente Prudente, SP. Mestre em Educação para a Ciência e o Ensino de Matemática pela Universidade Estadual de Maringá. Doutorando em Ensino de Ciências e Educação Matemática pela Universidade Estadual de Londrina. Professor do Instituto Federal de Educação, Ciência e Tecnologia de São Paulo, Campus de Presidente Epitácio - IFSP/PEP.

\section{Como citar este documento:}

DE PAULA, Enio Freire. APRENDIZAGEM EM GEOMETRIA NA EDUCAÇÃO BÁSICA. Reflexão e Ação, Santa Cruz do Sul, v. 26, n. 2, ago. 2018. ISSN 1982-9949. Disponível em: <https://online.unisc.br/seer/index.php/reflex/article/view/12053>. Acesso em: ___ doi: http://dx.doi.org/10.17058/rea.v26i2.12053. 